Vol. 1, No. 1, Juli 2017, 56-66

Available Online at https://ejournal.warmadewa.ac.id/index.php/kulturistik

DOI: dx.doi.org/10.22225/kulturistik.1.1.217

\title{
THE ANALYSIS OF FORMS AND MEANINGS OF PREFIXES FOUND IN BALI ADVERTISER
}

\author{
Dewa Ayu Kadek Claria \\ Universitas Warmadewa \\ dewaayuclaria@yahoo.com
}

\begin{abstract}
The title of this research is The Analysis Forms and Meanings of Prefixes Found in Bali Advertiser. The scopes of discussions in this research are the forms of prefixes found in Bali Advertiser and their meanings. The method in doing this research is qualitative research. The data source which is used in writing this research is Bali Advertiser, a newspaper which is used for advertisement for foreign community, and it is also used as the official English language media for the Direktorat Jenderal Pajak (Bali Tax Office). The main theory which is used in this research is the theory of Quirk in the book entitled $A$ University Grammar of English. The books which are used as supporting theory are Morphology by Katamba and English Word - Formation by Bauer. After collecting and analyzing the data, there are many forms and meanings of prefixes found, they are: negative prefixes such as non-, and in-, reversative or privative prefixes such as un- and dis-, pejorative prefixes that is mis-, prefixes of degree or size such as super-, out-, sur-, over-, ultra- and mini-, prefixes of attitude such as co- and anti-, locative prefixes that is inter-, prefixes of time and order such as pre-, ex-, and re-, number prefixes such as bi- and multi-, other prefixes such as auto- and semi-, and conversion prefixes such as be- and en-.
\end{abstract}

Keywords: Prefixes, Morphology, Affixation

\section{INTRODUCTION}

Morphology as a sub-branch of linguistics is the study of internal structure of word-form. The basic units of analysis recognized in morphology are morphemes (Bauer, 1983: 13). Morphemes are the smallest units of meaning (Katamba, 1993: 19). Morphemes have some types, such as roots, affixes, stems, bases, inflectional and derivational morphemes. A root is the core of a word with nothing else attached on it (Katamba, 1993: 41).

Affixes are morphemes that only occur when attached to some other morpheme or morphemes such as root or stem or base (Katamba, 1993: 44). A stem is the part of a word that is in existence before any inflectional affixes have been added. Affixes here are referred to affixes required by syntax such as markers of singular and plural number in nouns, tense in verbs, and so on (Katamba, 1993: 45). A base is any unit to which affixes of any kind can be added (Katamba, 1993: 45). Inflectional and derivational morphemes are used to form words in different ways. Derivational morphemes form new words by changing the meaning of the base or changing the word class, and inflectional morphemes form new words without changing both of them (Katamba, 1993: 47). Affixes are important in morphology because it allows us to form new words and express specific meanings of words that we commonly use.

Prefixes, suffixes, and infixes are the types of affixes. (Katamba, 1993: 44) asserts that a prefix is an affix attached before a root or stem or base. Suffix is an 
affix attached after a root or stem or base, and infix is an affix inserted into the root itself. Prefixation is a morphological process of adding prefix to the base, with or without change the word-class (Quirk, 1973: 430). A prefix is an affix added before a root or stem or base (Katamba, 1993: 44). The vast majority of prefixes in English are class-maintaining, and those can be added to the bases more than one form class (Bauer, 1983: 216).

Examples:

a. We know that the bridge was unsafe (Thomson, 1960: 195)

b. He dislikes sleeping long (Murthy, 2003: 119)

We can see from the examples above that prefixes are affixes which are attached before a root or stem or base. Prefix un- in example (a) is added before adjective 'safe'. In example (b), we also found that prefix dis- is attached to verb 'like' + suffix $-s$. They prove that prefixes can be added to the bases more than one form.

Every single suffixes in English has its own meaning and they have similar pattern in some cases (Munaf, 2009). Phenomenon or Russian prefixes of the striking polysemy (Tolskaya, 2014). He analyzed about the correlation between prefixes with classification of verb and he found that lexico-syntactic plays an important role for the interpretation of prefixes. There are 199 adjectives, 188 nouns and 266 verbs has been classified as the roots and she suggested the reader to apply derivational affixes by breaking the words into elements (Aryati, 2014).

The Affixation used in Avenged Sevenfold's Lyric, he found that some affixation did exist as inflectional and derivational affixes and he concluded that affixational affixes are less dominant than derivational affixes (Budiman, 2016).

The translation prefixes form on the basis of parallel corpora. He found that some form were able to create without losing their verbal character (Podolak, 2016).

Based on the explanation above, it is very interesting to analyze affixes because affixes play an important role in morphology. Affixes have complex explanation if it is discussed in each sub-chapter. Because of that, in this reserach, only prefixes will be discussed in detail. There are two problems that will be discussed in this research, they are hat are the forms of prefixes found in Bali Advertiser? And what are the meanings of prefixes found in Bali Advertiser?

\section{METHODS}

This study was basically conducted in a qualitative approach. The methods in doing this research are applied in three steps; they are data source, data collection, and data analysis. These steps will be described as seen below:

The data source of this research is taken from Bali Advertiser with the license code of SIUPP No. 1593/SK/MENPEN/SIUPP/1999. Bali Advertiser is used for advertisement for foreign community, and it is also used as the official English language media for the Direktorat Jenderal Pajak (Bali Tax Office). In this news research, it could be found many words which are formed by prefixes.

For the data collection, it could be done by these steps. First, the data source is read carefully. And then, the words which are formed by prefixes are highlighted. Afterwards, they are collected by quoted and classified according to their forms.

The analysis is done by giving data in the format of sentences that con- 
tained of words formed by prefixes which are found in data source. Later, the words formed by prefixes are analyzed based on their forms. After that, the meanings of those words are analyzed. The analysis is done according to the theories applied. The main theory which is used in this paper is the theory of prefixes proposed by Quirk and Greenbaum in the book entitled A University Grammar of English.

\section{DISCUSSION}

There are ten prefixes found in the data source. The prefixes found are negative prefixes, reversative or privative prefixes, pejorative prefixes, prefixes of degree or size, prefixes of attitude, locative prefixes, prefixes of time and order, number prefixes, other prefixes, and conversion prefixes.

\section{Negative Prefixes}

Negative prefixes are the prefixes that carry negative meaning in word formation, such as prefix un- which means 'the opposite of' or 'not', non- which means 'not', in- which has meaning as for un-, dis- which has meaning as for un-, and prefix $a$ - which means 'lacking in'

Prefix non- is used to express negative meaning of 'not'. It is also used to say that someone or something is not a particular thing, or does not do a particular thing. Non- can normally be regarded as corresponding to clause negation.

Example:

1. APTOS STITCH LIFT a non-surgical mini face lift that will last for 5 to 7 years (Bali Advertiser, 2017: 55).

In examples above, we found that prefix non- is attached to adjectives. Prefix non- is used to express negative meaning of 'not'. In example (1), we see that prefix non-is added to adjective 'surgical' which is the root and base of nonsurgical. Therefore, non-surgical is a derivational morpheme which has the same meaning with 'not surgical'. It can be paraphrased into 'APTOS STITCH LIFT a not surgical mini face lift that will last for 5 to 7 years'.

Prefix in-is also one of prefixes which carries negative meaning. Prefix inhas function as for $u n$-, that is to express 'not' or 'the opposite of', and it is usually attached to adjective.

Example:

2. Take antiseptic hand cleaner with you - it's inexpensive and available in apoteks (Bali Advertiser, 2017: 29).

We also can see that prefix in- is added to adjective 'expensive' which is the root and base of inexpensive in the example above. Thus, the word inexpensive has the equal meaning to 'not expensive' or 'not costing much money' or 'cheap'. Inexpensive can be paraphrased into 'Take antiseptic hand cleaner with you - it's not expensive and available in apoteks ...'.

\section{Reversative or Privative Prefixes}

Reversative prefixes or privative prefixes are the prefixes which carry reversative or privative meaning in the word formation. Those prefixes are prefix $u n$ - that means 'to reverse action' and 'to deprive of', prefix de- which means 'to reverse action', and prefix dis- which has meaning as for un-. 
Besides carrying negative meaning, prefix un- sometimes carries reversative or privative meaning. Prefix $u n$ - is used to make sense of 'to reverse action' and 'to deprive of'. It is usually added to verbs.

Example:

3. In order to boost blood flow to your sexual organs you need to clean out and unblock your arteries, remove inflammation, and correct diabetes if it is present (Bali Advertiser, 2017: 58).

In the italic word unblock above, we see that prefix un- is attached to verb 'block' which is the root and base of unblock. Prefix un- is used to make sense of 'to reverse action'. Thus, unblock is a derivational morpheme that may express 'to reverse block'. It may be paraphrased into 'In order to boost blood flow to your sexual organs you need to clean out and reverse block your arteries ...'

This prefix also carries reversative or privative meaning. It has the same function as for $u n-$, that is as 'to reverse action' and 'to deprive of'. Example:

4. They are dissatisfied with their lives and themselves, because they don't feel accepted by their community or are unwilling to accept others who are different from them. This 'dissatisfaction' has become a worldwide epidemic that is spreading across continents like a plague (Bali Advertiser, 2017: 60).

The example above shows us that prefix dis- is added to noun 'satisfaction' which is the base of dissatisfaction that belongs to derivational morpheme. Prefix dis- is used as 'to reverse action' and 'to deprive of'. Therefore, dissatisfaction is equivalent to feeling of not being satisfied'. It can be paraphrased into '... This 'feeling of not being satisfied' has become a worldwide epidemic that is spreading across continents like a plague'.

\section{Pejorative Prefixes}

Pejorative prefixes are the prefixes which carry pejorative meaning. The prefixes which are included in the group of pejorative prefixes are mis- which means 'wrongly' or 'astray', mal- that means 'bad(ly)', and pseudo- that means 'false' or 'imitation.

Prefix mis- can be added to verbs, abstract nouns, and participles. But in this research, the example of prefix mis- attached to abstract noun is the only example that can be found in the data source.

Example:

5. Through our own misperceptions, limiting beliefs and patterns, we become stuck in our lives and remain unhappy (Bali Advertiser, 2017: 60).

The word misperception shown us that prefix mis- is added to abstract noun 'perception' which is the root and base of misperception. Prefix mis- carries the meaning of 'wrongly' or 'astray', and it belongs to derivational morpheme. Therefore, misperceptions has equal meaning as 'wrongly perceptions'. Misperceptions can be paraphrased into '... Through our own wrongly perceptions, limiting beliefs and patterns, we become stuck in our lives and remain unhappy'.

\section{Prefixes of Degree or Size}

These prefixes are the prefixes which carry the meaning of degree or size. 
There are ten prefixes of degree or size, they are prefix arch-, super-, out-, sur-, sub-, over-, under-, hyper-, ultra-, and mini-. Prefix arch-carries the meaning of 'highest' and 'worst', super- means 'above', 'more than' and 'better', out- means 'to do something faster, longer, etc than...', sur- means 'over and above', subhas sense of 'lower than' or 'less than', over- has meaning of 'too much', undermeans 'too little', hyper means 'extremely', ultra- means 'extremely' and 'beyond', and mini- has sense of 'little'. These prefixes are discussed as follows.

Prefix super- is used to make sense of 'above', 'more than' and 'better'. This prefix can be added to nouns and adjectives.

Example:

6. This super cute, brand new villa is nestled amongst some of Bali's finest villa complexes in a central location (Bali Advertiser, 2017: 22).

In the example number six (6), we found that super- is attached to adjective 'cute' which is the root, base and stem of super cute which belongs to inflectional morpheme. Super cute has equal meaning as 'more than cute'. It may be paraphrased into 'This more than cute, brand new villa is nestled amongst some of Bali's finest villa complexes in a central location'.

This prefix is used to make sense of 'to do something faster, longer, etc than...', and it is usually added to verbs. There is an example of prefix out- which is found in the data.

Example:

7. For Sale; Misc. car accessories: Base racks Thule Xpedition 821 (Rp. 4 juta), roof rails system Thule 755 (Rp. 1,5 juta), outride bike rack Thule 561 (Rp. 1 juta), portable fridge Waeco TropiCool (Rp. 1,5 juta) (Bali Advertiser, 2017: 16).

The example above showed that prefix out- is attached to verb 'ride' which is the root, base and stem of outride that belongs to inflectional morpheme. Prefix out- is used to make sense of 'to do something faster, longer, etc than...'. Thus, the word outride is equivalent to 'to ride faster than ...' or 'to ride faster or further than someone else'. Then it may be paraphrased into '... rack Thule 561 of bike that could ride faster (Rp. 1 juta) ...'

Prefix sur- carries the meaning of 'over and above'. Sur- is usually added to noun. In this research, we can see one example of prefix sur-which is found in the data source.

Example:

8. Fare featured is for return flights from 1 September till 15 December 2017 and excludes taxes and surcharges. Sales end 30 November 2017 (Bali Advertiser, 2017: 13).

We found in example above that prefix sur-is added to noun 'charges' that is the base and stem of surcharges. Prefix sur-carries the sense of 'over and above'. The word surcharges can be paraphrased into 'Fare featured is for return flights from 1 September till 15 December 2017 and excludes taxes and extra charges ...'

Prefix over- carries the meaning of 'too much'. This prefix is usually attached to verbs, participles and adjectives. 
Example:

9. Be very careful that you don't overstep the bounds and keep your cool as much as possible (Bali Advertiser, 2017: 50).

The italic prefix over- is attached to verbs. This prefix has a function as 'too much'. We have found in example nine (9) that prefix over- is added to verb 'step' which is the root, base and stem of overstep. The word overstep is an inflectional morpheme which has same meaning as 'too much step'. So, the word overstep in example above can be paraphrased into 'Be very careful that you don't do not step to much and keep your cool as much as possible'

Prefix ultra- carries the meaning of 'extremely' or 'beyond'. This prefix is usually attached to adjectives.

Example:

10. $100 \%$ bamboo bed linens and towels for hotels, villas and private homes. Feel the difference. Make a difference... ultrasoft, durable, sustainable (Bali Advertiser, 2017: 31).

Prefix Ultra- shown by the word ultrasoft where prefix ultra- is added to adjective 'soft' which is the root, base and stem of ultra soft. Prefix ultra-carries the sense of 'extremely' or 'beyond'. So, it can be concluded that the word ultra soft is an inflectional morpheme that has the same meaning as 'extremely soft'. The word ultra soft can be paraphrased into ' $100 \%$ bamboo bed linens and towels for hotels, villas and private homes. Feel the difference. Make a difference... extremely soft, durable, sustainable',

The last prefix of degree or size is prefix mini- Prefix mini- is used to make sense of 'little', and usually added to nouns. It often used for humorous coinages. Example:

11. A witness at Mirah Minimarket, opposite the foot massage shop, said he had seen four plain-clothes police officers outside from 11am (Bali Advertiser, 2017: 66).

In example eleven (11), prefix mini- is attached to noun 'market' which is the root, base and stem of minimarket that belongs to inflectional morpheme. We can conclude that minimarket has the same meaning with 'little market', and it can be paraphrased into 'A witness at Mirah little market, opposite the foot massage shop, said he had seen four plain-clothes police officers outside from 11am'.

\section{Prefixes of Attitude}

Prefixes of attitude are the prefixes used to form words so that they have certain attitudes. Those prefixes are co- which carries sense of 'with' or 'joint'-, counter-which is used as 'in opposition to', anti- as 'against', and pro- as 'on the side of'. They are discussed as follows.

The first prefix of attitude is prefix co-. Prefix co- is used to create sense of 'with' or 'joint'. There is an example of prefix co- which is found in the data source.

Example:

12. Renee Levi, Ph.D., Co-Director of the Powers of Place Initiative (a US based not for profit organization), research study just completed (Bali Advertiser, 2017: 25). 
In example above, we found that prefix co- is attached to noun 'director' which is the base of director. Prefix co- carries the meaning of 'with' or 'joint' or 'together' or 'doing something with someone else as an equal or with less responsibility'. So, co-director has the same meaning as 'with director' or 'together with director' or 'someone who helps a director', and it belongs to derivational morpheme. The word co-director may be paraphrased into 'Renee Levi, Ph.D., someone who helps the director of the Powers of Place Initiative ...'

This prefix is used to make sense of 'against'. Prefix anti- suggests simply an attitude of opposition.

Example:

13. Bambula Bamboo Furniture Factory \& Showroom. Dry Bamboo + Anti Bug Guarantee. (Bali Advertiser, 2017: 36).

In example thirteen (13), prefix anti- is added to noun 'bug' which is the root and base of anti-bug. The word anti bug has the same meaning with 'against bug' or 'opposed to bug' or 'acting to prevent the emergence of bug', and it belongs to derivational morpheme. It can be paraphrased into '... Dry Bamboo + substance that is used to prevent the emergence of bug Guarantee'

\section{Locative Prefixes}

Locative prefixes are used to form words so that they could indicate location, such as super-, sub-, inter-, and trans-. Prefix super-carries the sense of 'over', sub- has meaning as 'beneath' and 'lesser in rank', inter- as 'between' or 'among', and trans- as 'across, from one place to another'. Each of these prefixes is discussed as follows.

Prefix inter- carries the sense of 'between' or 'among'. It can be attached to denominal adjectives, verbs, and nouns.

Example:

14. For those wondering where 'Fabulously Feet' went from Sunset Rd? Recently spotted, on the left hand side of the By Pass Sanur before you arrive at the big intersection with McDonalds on the right (Bali Advertiser, 2017: 15).

In example above, we found that prefix inter- is added to noun 'section' which is the root and base of intersection. Inter- is used to create the meaning of 'between' or 'among'. So, it can be concluded that intersection is a derivational morpheme which may express 'between section' or 'among section' or 'a place where two or more roads intersect'. The sentence in example above can be paraphrased into '.. On the left hand side of the By Pass Sanur before you arrive at the big place where sections intersect with McDonalds on the right'.

\section{Prefixes of Time and Order}

Prefixes of time and order are used to indicate time and order, such as fore, pre-, post-, ex-, and re-. Prefix fore- and pre- carry the meaning of 'before', prefix post-- has a meaning as 'after', ex- as 'former', and re- as 'again' or 'back'. This prefix carries the sense of 'before'. Prefix pre- is usually added to nouns and adjectives.

Example:

15. MamaSan has been preceded by a pre-opening buzz like no other restaurant in Bali! (Bali Advertiser, 2017: 19). 
We have found in example above that prefix pre- is added to nouns. Prefix pre- carries the sense of 'before' and 'in preparation'. In example fifteen (15), pre - is attached to noun 'opening' which is the base of pre-opening that belongs to derivational morpheme. The word pre-opening has the same meaning as 'before opening' or 'in preparation opening'. Pre-opening may be paraphrased into 'MamaSan has been preceded by a preparation opening buzz like no other restaurant in Bali!'

Prefix $e x$ - is used to create the sense of 'former'. Prefix $e x$-is usually added to human nouns.

Example:

16. Warehouse for lease 1000sqm, 8 large office space on 2 floors, workshop $600 \mathrm{sqm}$, water, electricity $33.000 \mathrm{kwt}$. Parking area $250 \mathrm{sqm}$. Very central, ex garment factory close to Jl. Mertanadi. Minimum 10yrs. 150jta/yr. Contact: 087860064852 (Bali Advertiser, 2017: 83).

In example above, we found that prefix ex- is added to noun 'garment' which is the root and base of ex garment that belongs to derivational morpheme. Prefix ex-carries the meaning of 'former', so ex garment is equivalent to 'former garment'. The sentence in example above can be paraphrased into '... Parking area $250 \mathrm{sqm}$. Very central, former garment factory close to Jl. Mertanadi ...'

This prefix can be used to express 'again' and 'back'. Prefix re- is usually attached to verbs and abstract nouns.

Example:

17. Nothing in Bali Advertiser can be reproduced in whole or in part, either in print based media or in internet based media, without the written permission of the publisher (Bali Advertiser, 2017: 2).

Prefix re- expresses 'again' and 'back'. In example seventeen (17), we found that prefix re- is attached to verb 'produced' which is the base of reproduced. So, reproduced is a derivational morpheme which has equal meaning as 'produced again'. It may be paraphrased into 'Nothing in Bali Advertiser can be produced again in whole or in part ...'

\section{Number Prefixes}

Number prefixes are the prefixes used to indicate a certain number. Those prefixes are uni- , mono-, bi-, di-, tri-, multi-, and poly-. Uni- and mono- have the same meaning as 'one', $b i$ - and $d i$ - as 'two', tri- as 'three', then multi- and polyas 'many'.

This prefixes are used to indicate the number of 'two'. In Bali advertiser, there are many data contains of prefix $b i$-.

Example:

18. Wide experience with the administration of bi-lateral and multi-lateral grants including on-site fieldwork implementation and logistics management (Bali Advertiser, 2017: 77).

We can see in the above sentence that $b i$ - is attached to adjective 'lateral' which is the root and base of bi-lateral. Bi- has the meaning of 'two'. Thus, bilateral is a derivational morpheme that may express 'two lateral' or 'having two sides' or 'involving two groups or nations'. It can be paraphrased into 'Wide ex- 
perience with the administration of two lateral and multi-lateral grants ...'

These prefixes are used to express 'many'. There are some examples of prefix multi-which are found in the data source.

Example:

19. More than 1,200 accredited specialists covering over 40 multi-disciplinary specialties (Bali Advertiser, 2017: 54).

We see from example above that prefix multi- are added to adjectives. This prefix carries the meaning of 'many. Multi- is attached to 'disciplinary' which is the base of multi-disciplinary. The word multi-disciplinary is a derivational morpheme that may express 'many disciplinary' or 'involving people with different jobs or from different areas of study'. It can be paraphrased into 'More than 1,200 accredited specialists covering over 40 many disciplinary specialties'.

\section{Other Prefixes}

There are also some other prefixes, like auto-, neo-, pan-, proto-, semi-, and vice--. Auto- is equivalent to 'self', neo- has sense as 'new' or 'revived', pan- as 'all' or 'world-wide, proto- as 'first' or 'original', semi- as 'half', and vice- as 'deputy'.

Prefix auto- is used to create the meaning of 'self'. There is an example which can be found in the data. They can be seen as follows.

Example:

20. Question: We have been told, and signs point to it, that my wife has an autoimmune disease called SLE. It has something to do with the 'lupus' affecting the kidneys (Bali Advertiser, 2017: 61).

In example above, we found that prefix auto- is added to adjective 'immune' which is the root and base of auto-immune. Prefix auto- carries the meaning of 'self'. Therefore, auto-immune is a derivational morpheme which may express 'self immune'. Auto-immune may be paraphrased into 'We have been told, and signs point to it, that my wife has a self immune disea se called SLE ...' Example:

This prefix expresses 'half'. It is usually attached to adjectives and nouns.

21. CANGGU: 2 bed, 2 bath, AC, Water heater, Indoor Balinese house, cute garden, semi furnished. ID: 505914. 60 mil pa (Bali Advertiser, 2017: 84).

We found also that prefix semi- is attached to adjective 'furnished' which is the base of semi furnished. The word semi furnished has the same meaning as 'half furnished', and it belongs to derivational morpheme. The sentence in example twenty first (21) may be paraphrased into 'CANGGU: 2 bed, 2 bath, AC, Water heater, Indoor Balinese house, cute garden, half furnished. ID: 505914. 60 mil pa'.

\section{Conversion Prefixes}

Some other prefixes have function to change the word-class of nouns, verbs, and adjectives, such as $b e-, e n-$, and $a-B e-$ is used to change the word class of noun into participial adjective. En- is used to change noun into verb, and $a$ - is used to alter verbs into predicative adjective.

This prefix is used to change the word class of noun into participial adjec- 
tive. It is also used to change the word class of verb, adjective, and noun into transitive verb. Prefix be-may express 'treat someone or something in a particular way'. In this case, it is found an example of prefix be- which is added to verb. It can be seen as follows.

Example:

22. Nonetheless, the little bottles of hand cleaner are a practical way to keep clear of many of our beloved Bali's health problems (Bali Advertiser, 2017: 29).

Prefix be-is used to alter noun into participial adjective. But in this case, we see that prefix be-is attached to verb 'loved' which is the base of beloved that belongs to derivational morpheme. Thus, beloved is the participial adjective which is converted from verb 'loved'. Be-carries the meaning of 'treat someone or something in a particular way', so beloved may express 'treat someone or something with love' or 'much love by' or 'loved very much by someone'. It may be paraphrased into 'Nonetheless, the little bottles of hand cleaner are a practical way to keep clear of many of our health problems in Bali which is loved very much'.

Prefix en- is used to alter the word class of noun into verb. En- carries the sense of 'to make someone or something be in a particular state or have a particular quality'.

Example:

23. Ideally, a mix of all of these types of happiness can deeply enrich our lives, but in reality, we can't be happy all of the time (Bali Advertiser, 2017: 60).

Prefix en- is used to alter the word class of noun into verb. En- may express 'to make someone or something be in a particular state or have a particular quality'. In example twenty third (23), we found that prefix en- is attached to noun 'rich' which is the root and base of enrich. So, enrich is a verb that is converted from noun 'rich', and it is equivalent to 'to make someone or something rich or richer' or 'to improve the quality of something, especially by adding things to it'. The sentence in example above can be paraphrased into 'Ideally, a mix of all of these types of happiness can deeply make our lives rich ...'

\section{CONCLUSION}

The conclusion of the analysis can be seen as follows. The forms of prefixes which are found and their meanings are prefix non-, and in- which express negative meaning, prefix un- and dis- which express reversative or privative meaning, prefix mis- which expresses pejorative meaning, prefixes of degree or size which are represented by prefix super-, out-, sur-, over-, ultra- and mini-, prefixes of attitude which are expressed by prefix co- and anti-, prefix interwhich expresses locative meaning, prefixes of time and order which are indicated by prefix pre-, ex-, and re-, number prefixes which are represented by $b i$ - and multi-, other meanings of prefixes which are expressed by auto- and semi- and the last are $B e$ - and en-which indicate conversion prefixes with various meanings.

\section{REFERENCES}

Advertiser, B. (2017). Bali Advertiser 19th March - 2nd April 2017.

Aryati, S. M. (2014). An analysis of derivational affixes in the land of five towers novel. Kudus: Universitas Muria Kudus. 


\section{Lisulturisistinlk \\ KULTURISTIK JURNAL BAHASA \& BUDAYA}

Vol. 1, No. 1, Juli 2017, 66

Available Online at https://ejournal.warmadewa.ac.id/index.php/kulturistik

DOI: dx.doi.org/10.22225/kulturistik.1.1.217

Bauer, L. (1983). English word formation. Cambridge: Cambridge University Press.

Budiman, A. (2016). The affixation used in avenged sevenfold's lyrics. Yogyakarta: Islamic University Sunan Kalijaga.

Katamba, F. (1993). Morphology. Houndmills: Macmillan Press LTD.

Munaf, K. (2009). A contrastive study between English and Indonesian suffixes. Sumatra: Universitas Sumatra Utara.

Murthy, J. D. (2003). A contrastive study between English and Indonesian suffixes. Sumatra: Universitas Sumatra Utara.

Podolak, M. (2016). Russian verbal prefixes. Conpenhagen: University of Conpenhagen.

Quirk, R. and S. G. (1973). A university grammar of English. Harlow: Longman Group Limited.

Thomson, A. J. and A. V. M. (1960). A practical English grammar. New York: Oxford University Press.

Tolskaya, I. (2014). Verbal prefixes: selection and interpretation. Norway: University of Tromso. 